\title{
Comparative Study of Oil Recovery Factor Determination for Edge and Bottom Water Drive Mechanism Using Water Influx Models
}

\author{
C. G. J. Nmegbu, Orisa F. Ebube, and Emmanuel Aniedi Edet
}

\begin{abstract}
The purpose of this research work is to comparatively study the oil recovery factor from two major aquifer geometry (Bottom and Edge water aquifer) using water aquifer model owing to the fact that most if not every reservoir is bounded by a water aquifer with relative size content (Most Large). These aquifers are pivotal in oil recovery factor (percent\%), Cumulative oil produced (MMSTB) as well as overall reservoir performance the methodology utilized in this study involves; Identification of appropriate influx models were utilized for aquifer characterization. The characterizes of the Niger Delta reservoir aquifer considered include aquifer permeability, aquifer porosity etc. Estimation of aquifer properties is achieved by using regressed method in Material Balance Software (MBAL). This approach involves History Matching of average reservoir pressure with computed pressure of the reservoir utilizing production data and PVT data. The computed pressure from model is history matched by regressing most uncertain parameters in aquifer such as aquifer size, permeability, and porosity. Historic production data was imputed into the MBAL Tank Model, the production data was matched with the model simulation by regressing on rock and fluid parameters with high uncertainty. The match parameters were recorded as the base parameter and other sensitivity on aquifer parameters using the Fetkovich model for the bottom and edge water drive. The average percentage increase in oil cumulative volume was $0.40 \%$ in fovour of bottom water drive. Further sensitivity on cumulative oil recovered showed the increase in reservoir size with increasing aquifer volumes increases oil production exponentially in bottom water drive whereas edge water drive increased linearly. Aquifer volume, aquifer permeability showed linear relationship with bottom and edge water drive.
\end{abstract}

Index Terms - Oil Recovery Factor, Edge water drive, Bottom water drive, Water Influx model, Sensitivity.

\section{INTRODUCTION}

Petroleum reservoir drive mechanisms are often associated in some form or another with formation waters as nearly all hydrocarbon reservoirs are bounded by water-bearing rocks called aquifers which is a major source of water influx (water encroachment). Although there are other sources of water movement into the reservoir which includes recharge of the reservoir by surface water from outcrops and water injection from the surface to supplement a weak aquifer [1] This aquifer maybe larger than the hydrocarbon reservoir that

Submitted on June 07, 2021.

Published on July 02, 2021.

C. G. J. Nmegbu, Rivers State University, Nigeria.

(e-mail: gnmegbu@ ${ }^{\text {gmail.com}) ~}$ adjoin as to appear infinite in size, or they may be so small in size. Reservoir drive mechanisms may be from the expansion of connate water within the gas or oil reservoir or from an external aquifer at the edge of the reservoir, or from an underlying aquifer. High permeability reservoirs are often in contact with an aquifer that provides pressure support through water influx. A drop in the reservoir pressure due to fluid production causes the aquifer water to expand and flow into the reservoir. That is to say as reservoir fluids are produced and reservoir pressure declines, a pressure differential develops from the surrounding aquifer into the reservoir. Hence, it is needful to characterize the reservoir-aquifer system.

Reservoir-aquifer systems are classified based on; degree of pressure maintenance, flow regimes, outer boundary conditions, flow regimes, and flow geometrics [2]. But for the purpose of this study an aquifer will be classified based on flow geometries edge water-drive and bottom-water drive The conceptual influx of water into the petroleum reservoir is illustrated in Fig. 1.

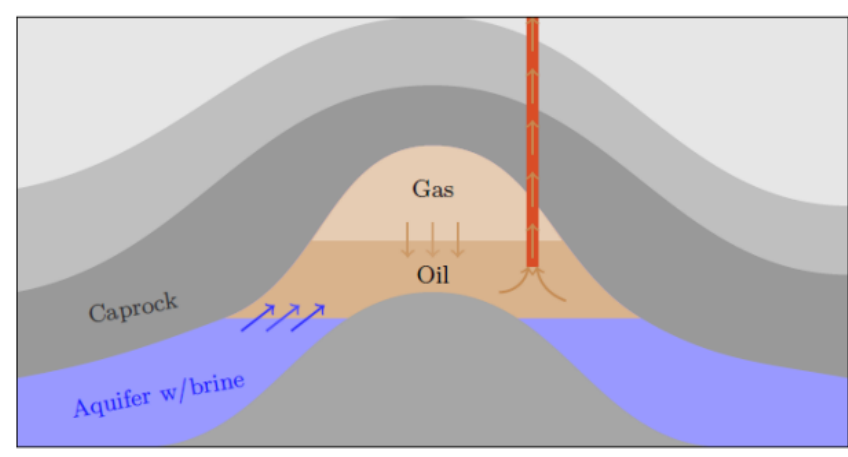

Fig. 1. Conceptual Influx of Water into the Petroleum Reservoir [3]

Water influx volume as well as the flow geometrics has a significant role to play in the recovery factor. Estimation of water influx volumes into the reservoir is significant in number of applications such as material balance for estimation of reserves, reservoir simulation studies for model calibration, production scheduling and setting up development strategies to optimize hydrocarbon recovery [4]. An accurate estimation of water influx into the reservoir is required with the aid of an efficiency aquifer model that can capture the real dynamics of petroleum subsurface system.

Orisa F. Ebube, Emerald Energy Institute, University of Port Harcourt, Nigeria.

(e-mail: ebubeorisa ${ }^{@}$ yahoo.com)

Emmanuel Aniedi Edet, Rivers State University, Nigeria.

(e-mail: eemmanuelaniedi@gmail.com) 
Further, it is important to characterize the aquifer behaviour before start aquifer modelling or inclusion of aquifer into the reservoir simulation model. This is because during aquifer characterization, the understanding of aquifer properties and strength is increased.

Aquifer characterization is a challenging task in aquifer modelling. This is because most of aquifer properties such as aquifer size, aquifer permeability, aquifer porosity and water encroachment angle are uncertain. One of the main reasons is the cost of drilling wells into the aquifer to gain necessary information is often not justified [5]. This is reasonable; however, the uncertainties associated with aquifer properties should be reduced to have an efficient aquifer model.

\section{A. Aims and Objective}

This research work is aimed at studying comparatively the oil recovery factor from edge water and bottom water drives using Fetkovich steady-state water influx model.

\section{LITERATURE REVIEW}

\section{A. Recovery Factor}

Oil companies will want to maximize the value of a field by getting as much of the hydrocarbons out of it as possible. However, it is not feasible to recover the entire hydrocarbon from a reservoir. Only a certain percentage of the total hydrocarbons will be recovered from a field, and this is known as recovery factor [6]. Recovery factor are higher in gas fields than they are in oil fields. Typical recovery factors for gas are about $50-80 \%$ [7]. There is more scope to improve oil recovery. Global recovery factors for oil are thought to be in the range of 30-35\% [6]. Mathematical formulation for determination of recovery factor is presented in literature review where the General material balance equation (GMBE) is utilized.

\section{B. Classification of Reservoir Aquifer Systems}

A reservoir-aquifer system implies a reservoir that is surrounded or bounded with an aquifer. A sedimentary rock formation located subsurface at elevated temperature and pressure characterized with good permeability and porosity to store and transmit fluid is referred as a reservoir. While a water bearing rock is called an aquifer [8]. The fluids referred in this contest are oil, gas, and water. Reservoir-aquifer systems are commonly classified based on the following four categories [2].

Degree of Pressure Maintenance:

1. Outer boundary conditions;

2. Flow regimes;

3. Flow geometrics.

\section{Outer boundary conditions}

The aquifer can be classified as infinite or infinite (bounded). Geologically all formations are finite but may act as infinite if the changes in the pressure at the oil-water contact are not felt at the aquifer boundary. Some aquifer outcrops are infinite acting because of surface replenishment. In general, the outer boundary governs the behavior of the aquifer and, therefore:

i. Infinite system indicates that the effect of the pressure changes at the oil/aquifer boundary can never be felt at the outer boundary. This boundary is for all intents and purpose at a constant pressure equal to initial reservoir pressure.

ii. Finite system indicates that the aquifer outer limit is affected by the influx into the oil zone and that the pressure at this outer limit changes with time [2].

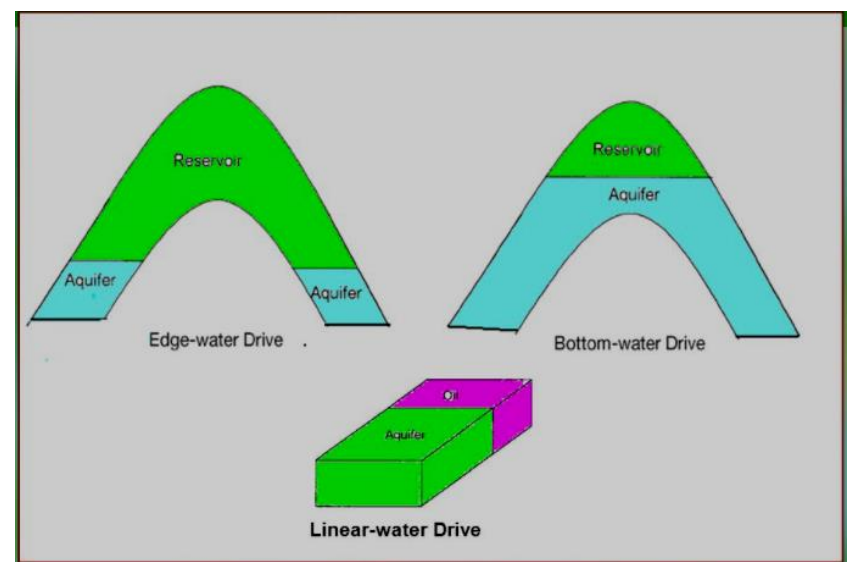

Fig. 2. Flow Geometries Describing Water Influx into the Reservoir [2].

\section{Flow Regimes}

Three flow regimes are basically considered in describing fluid flow in the reservoir. These are steady state, semi-steady state (pseudo-steady state), and unsteady state. Steady state flow regime occurs when the rate of change of pressure at every location in the reservoir is zero. This is when the reservoir is supported by pressure maintenance operations or when there is a recharge from strong aquifer. Semi-steady state occurs when the rate of change of pressure is constant and unsteady state flow regime occurs when the rate of change of pressure is not zero or constant [2].

\section{E. The Combination-Drive Mechanism}

The driving mechanism most commonly encountered is one in which both water and free gas are available in some degree to displace the oil toward the producing wells. Two combinations of driving forces can be present in combination drive reservoirs. For instance, depletion drive and a weak water drive, depletion drive with a small gas cap and weak water drive [2].

\section{F. Water Influx Models}

Water influx models are mathematical models that simulate and predict cumulative water influx into the reservoir. Various researchers have proposed models that estimate cumulative water influx into the reservoir. Out of them three models are considered more realistic to date: the van Everdingen-Hurst model, Carter-Tracy model and Fetkovich model [9]. The following are some of models applied in estimating water influx into the reservoir listed based on author.

i. Pot aquifer model;

ii. Schilthius Steady-State Model;

iii. Hurst's modified steady-state model;

iv. van Everdingen and Hurst unsteady-state model;

v. Coats model or Allard and Chen model;

vi. Carter Tracy water influx model and;

vii. Fetkovich water influx model. 


\section{G. Pot aquifer model}

In this model, the aquifer pressure is assumed to be at equilibrium with the boundary pressure. The model is valid when the size of the aquifer is very small compared with the size of the reservoir and when the fluid transmissibility between the aquifer and the reservoir is very large. In addition, when the size of the aquifer is larger than the size of the reservoir the model becomes unrealistic [10]. The model is simple and uses the basic definition of compressibility with time independent material balance as shown in (3) [2], [11]. The compressibility is defined mathematically as:

$e_{w}=\frac{d W_{e}}{d t}=B_{o} \frac{d N_{P}}{d t}+\left(G O R-R_{s}\right) \frac{d N_{p}}{d t} B_{g}+\frac{d W_{p}}{d t} B_{w}$

or

$\Delta V c V \Delta p$

Correlating the above definition of compressibility definition to the aquifer gives:

Water influx $=$ (aquifer compressibility) (initial volume of water) (pressure drop):

$w_{e}=C_{t} w_{i}\left(p_{i}-p\right)$

It should be noted that, Equation 2.3suggests water influx is coming radially from all direction. This condition becomes unrealistic in case the reservoir is not circular in nature. Equation (5) shows modification made to (3) to account the flow mechanism by adding fractional influx angle [2]. It could be suggested that for larger aquifers, a mathematical model should be used that include time dependent variable to account the fact that it takes a finite time for aquifer to respond to the pressure changes into the reservoir [11].

The definition of the fractional influx angle (f) is shown in (4).

$f=\frac{\text { enchroachment ange in degrees }}{360^{\circ}}=\frac{\theta}{360^{\circ}}$

where

$w_{i}=\left[\frac{\pi\left(r_{a}^{2}-r_{e}^{2}\right) h \emptyset}{5.615}\right]$

\section{H. Schilthuis'Steady-State Model}

The model holds the steady state condition, that is the rate of change of pressure is equal to zero, and assumes the aquifer volume is very large than the reservoir volume such that the pressure at the external boundary of aquifer remains constant at initial pressure throughout the entire field life [9], [5].

The rate of water influx into the reservoir is proportional to the pressure drawdown, $\left(p_{i}-p\right)$ and can be determined by using Darcy equation as shown in Equation (6) [2], [5].

$\frac{d W_{e}}{d t}=e_{w}=\mathrm{C}\left(p_{i}-p\right)$

$$
\frac{d W_{e}}{d t}=e_{w}=\left[\frac{0.00708 k h}{\mu_{w} \operatorname{In}\left(\frac{r_{a}}{r_{e}}\right)}\right]
$$

The parameter $\mathrm{C}$ is called the water influx constant and is expressed in bbl/day/psi. This influx constant $\mathrm{C}$ may be calculated from the reservoir historical production data over a number of selected time intervals, provided that the rate of the water influx has been determined independently from a different expression.

In addition to that, one of the weaknesses of the Schilthuis' steady-state model is that as water is drained from the aquifer, the aquifer radius, ${ }^{r_{a}}$ and increases with time or in other word the length of invading water to reach to the reservoir increases with time [2], [5].

\section{Hurst's Modified Steady-State Model}

Hurst's in 1943 proposed a method to eliminate problem encountered in Schilthus's steady - state model by replacing dimensionless radius, $\frac{r_{a}}{r_{o}}$ with time dependent function, at The Hurst's modified steady-state model is shown in (8) [2].

$e_{w}=\frac{d W e}{d t}=\frac{0.00708 k h\left(p_{i}-p\right)}{\mu_{w} \operatorname{In}(a t)}$

The Hurst modified steady state equation can be written in a more simplified form as:

$e_{w}=\frac{d W_{e}}{d t}=\frac{C\left(p_{i}-p\right)}{\operatorname{in}(a t)}$

$C=\frac{0.00708 k h}{\mu_{w}}$

Equation (9) can be re-arranged as shown in (11) to (12) and a plot of $\left(\frac{p_{i}-p}{e_{w}}\right)$ versus in $(t)$ in log-log scale can be constructed provided that historical water influx rates, are available, for example determined separately using another technique such as material balance method. The trend line will give a slope of $\frac{1}{\mathrm{C}}$ and $\mathrm{y}$-intercept a value of $\frac{\operatorname{In} a}{\mathrm{C}}$ estimated when time $t=1$ as shown in Figure 3. In addition, Craft, Hawkins, \& Terry [5] pointed that Hurst's method is infrequently used because of limited application.

$\frac{p_{i}-p}{e_{w}}=\frac{\operatorname{In}(a t)}{C}$

$\frac{p_{i}-p}{e_{w}}=\frac{\operatorname{In}(a)}{C}+\frac{\operatorname{In}(t)}{C}$

The parameter $\mathrm{C}$ is a group of variables as shown in (10) which represent an overall driver for water influx into the reservoir. For example, when the parameter $\mathrm{C}$ is large the rate of water influx into the reservoir will increase and vice versa hold 


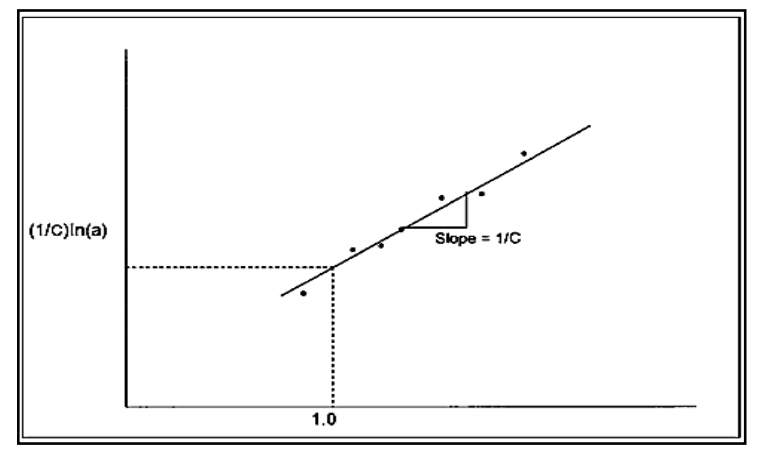

Fig. 3. Graphical Determination of Constants $\mathrm{C}$ and a in the Hurst's Modified Steady-State Model [2].

\section{J. van Everdingen and Hurst Unsteady-State Model}

The van Everdigen and Hurst model represents a mathematical model that estimate the cumulative water influx into the reservoir by using superposition principle. The authors solved the radial diffusivity equation for water influx into the reservoir by applying Laplace transformation. The detail of radial diffusivity equation and its derivation of the solution can be found in [13]. The model is applicable for determining water influx of the following systems: edge water-drive system, bottom water drive system and linear water-drive system as shown in Fig 2 The authors proposed solutions to the dimensionless diffusivity equation shown in Equation 2.16 for constant terminal rate and constant terminal pressure boundary conditions [2], [14].

In constant terminal rate boundary condition, the rate of water influx at the reservoir aquifer boundary is assumed to be constant and pressure drop at the interface of the reservoir aquifer system is calculated as a function of time.

While, for constant terminal pressure boundary condition, the constant pressure drop is assumed over finite period and water influx is calculated. In addition, various researchers recommend calculation of water influx into the reservoiraquifer boundary rather than pressure [2], [11], [5], [14].

This is because water influx into the reservoir is a function of time and pressure drop at the inner boundary condition of reservoir-aquifer system.

The dimensionless parameters are defined in (13) to (15) [5].

Dimensionless time: $t_{D}=0.0002637 \frac{k t}{\phi \pi r_{o}{ }^{2} C_{t}}$

Dimensionless radius: $r_{D}=\frac{r}{r_{o}}$

Dimensionless pressure: $P_{D}=\frac{p_{i}-p}{p_{i}-p_{w f}}$

$\frac{\partial P_{D}}{\partial r_{o}^{2}}+\frac{1}{r_{D}} \frac{\partial P_{D}}{\partial r_{D}}=\frac{\partial P_{D}}{\partial t_{D}}$

Equation (17) shows the cumulative water influx into the reservoir due to instantaneous pressure drop at the outer boundary. The value of water influx constant, $\mathrm{U}$, and dimensionless time, $t_{D}$ depends on the geometry of the reservoir- aquifer system. For example, for the radial aquifer geometry as shown in Fig 4, the equations for determining water influx constant and dimensionless time are shown in (18) and (19) respectively. Likewise, for linear aquifer geometry as shown in Figure 5, water influx constant and dimensionless time can be determined using (20) and (21) respectively [11].

$W_{e}=U \Delta p w_{D}\left(t_{D}\right)$

For radial aquifer in field units:

$$
U=1.119 f \phi h C_{t} r_{o}^{2}
$$

$\mathrm{t}_{\mathrm{D}}=$ Constant $x \frac{k t}{\phi \mu C_{t} r_{o}^{2}}$

The constant $=0.000264(\mathrm{t}$ in hours), 0.006634 ( $\mathrm{t}$ in hours), 2.309 ( $\mathrm{t}$ in years).

For linear aquifer in field units:

$$
\begin{aligned}
& U=0.1781 W L h c_{t}\left(\frac{b b l}{p s i}\right) \\
& t_{D}=\text { Constant } \times \frac{k t}{\phi \mu C_{t} L^{2}}
\end{aligned}
$$

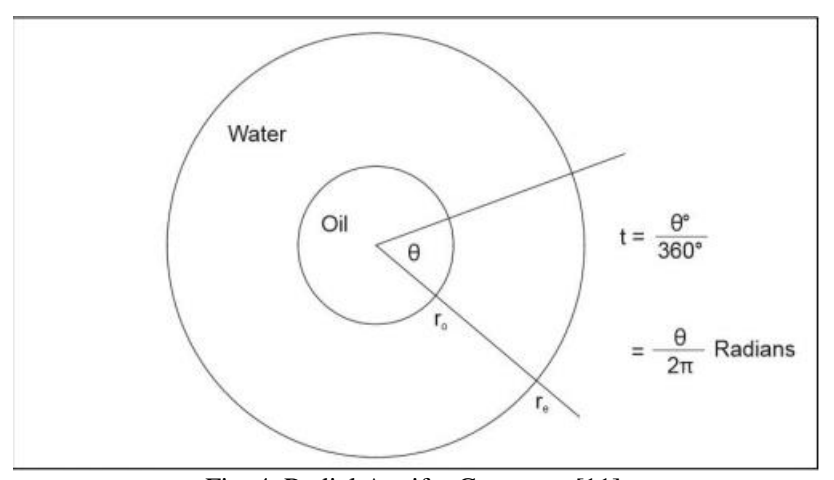

Fig. 4. Radial Aquifer Geometry [11].

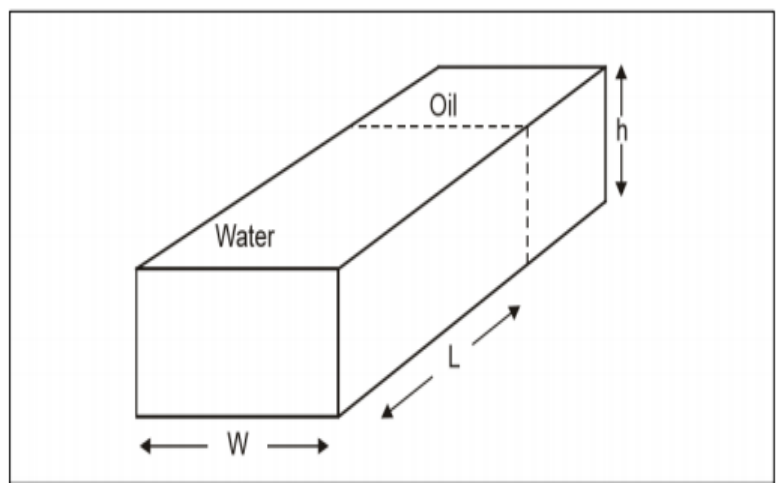

Fig. 5. Linear Aquifer Geometry [11].

Since (17) is usually used to calculate the cumulative water influx into the reservoir due to instantaneous pressure drop at the outer boundary; it is necessary to establish a relationship for calculating the total water influx at any given time during depletion stage. van Everdingen and Hurst proposed a concept of superposition which enables calculation of water influx at each successive pressure drop in the reservoiraquifer system. Equation (22) shows the application of superposition principle [2], [11].

$$
\begin{gathered}
W_{e}(T)=U\left[\Delta p_{o} W_{D}\left(T_{D}\right)+\Delta p_{1} W_{D}\left(T_{D}-t_{D 1}\right)+\right. \\
\Delta p_{2} W_{D}\left(T_{D}-t_{D 2}\right)+\cdots+\Delta p_{j} W_{D}\left(T_{D}-t_{D i}\right)+\cdots+ \\
\left.\Delta p_{n-1} W_{D}\left(T_{D}-t_{D n-1}\right)\right]
\end{gathered}
$$



(23):

Equation (22) can be written in general form as shown in

$$
W_{e}(T)=U \sum_{j=0}^{n-1} \Delta p_{j} W_{D}\left(T_{D}-t_{D j}\right)
$$

Few things to note regarding (23). The term $W_{D}\left(T_{D}-t_{D j}\right)$ does not represent two separate functions instead it stands for dimensionless cumulative water influx as a function of dimensionless time. The definition of dimensionless time has been presented in Equation 2.19 and is applicable for both early time influx, once the aquifer boundary effect has been felt and as well as for infinite aquifer case. Furthermore, the method of determining values of pressure drops, $\Delta \mathrm{p}$ was initially suggested by van Everdingen, Timmerman and McMahon by matching the continuous historical pressure decline at the reservoir-aquifer boundary by a series of discrete pressure step function as shown in Fig. 6.

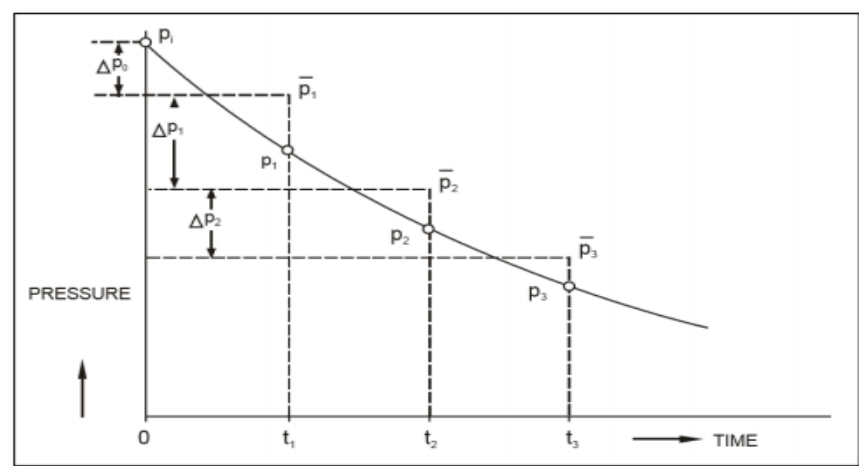

Fig. 6. Matching a Continuous Pressure Decline at the Reservoir-Aquifer Boundary by a Series of Discrete Pressure Step Function [11].

Equation (24) shows the calculations procedure for boundary pressure at the interface of the reservoir-aquifer system as an emphasize of Fig. 6.

$\overline{p_{n}}=\frac{p_{n-1}+p_{n}}{2}$

\section{K. Coats Model or Allard and Chen Model [12]}

Although, the van Everdingen and Hurst (VEH) model is considered the most exact water influx model for benchmarking available in the literature due to its faithfulness in describing the radial diffusivity equation of fluid flow in the reservoir or aquifer [1], [14], [15]. It is not adequately used to describe significant vertical water influx in bottom water drive system. To account the effect of vertical water movement into the reservoir, Coats in 1962 and later Allard and Chen in 1988 developed a mathematical model specifically for bottom water drive by modifying the diffusivity equation to consider the vertical flow in reservoiraquifer system as shown in (25) to (26) [2], [5].

$$
\begin{aligned}
& F_{k}=\frac{\text { Vertical permeability }}{\text { Horizontal permeability }} \\
& \frac{\partial^{2} p}{\partial r^{2}}+\frac{1}{r} \frac{\partial p}{\partial r}+F_{k} \frac{\partial^{2} p}{\partial z^{2}}=\frac{\mu \phi C_{t}}{k} \frac{\partial p}{\partial t}
\end{aligned}
$$

The solution developed by Allard and Chen for bottomwater drive system is identical to van Everdingen and Hurst as shown in Equation 2.27 [2]. Considering the following equations:

$$
\begin{aligned}
& z_{D}=\frac{h}{r_{o} \sqrt{F_{k}}} \\
& B=1.119 \phi h c_{t} r_{0}{ }^{2} \\
& W_{e}=B \Delta p W e_{D}\left(r_{D} t_{D} z_{D}\right)
\end{aligned}
$$

It is important to note that, water influx constant, B (28) does not include water influx angle, $\theta$, as in VEH model. In addition, the actual values of dimensionless cumulative water influx, are different from those of VEH model as now, $W e_{D}$ is the function of three parameters: Meanwhile, $r_{D}, t_{D}, z_{D}$ is dimensionless cumulative water influx in VEH model the function of only two parameters: $r_{D}, t_{D}, z_{D}$.

\section{Carter Tracy Water Influx Model}

In 1960 Cater and Tracy developed a simplified method of calculating direct water influx into the reservoir without using superposition principle. The method assumes constant water influx rate into the reservoir for each finite interval of time rather than constant terminal pressure as assumed by van Everdingen and Hurst method [16]. The cumulative water influx at any time, $t_{\mathrm{n}}$ are calculated using values obtained at previous time step, $t_{n}-1$ as shown in (30) [2].

$$
\begin{aligned}
& \left(W_{e}\right)_{n}=\left(W_{e}\right)_{n-1}+\left[\left(t_{D}\right)_{n}-\left(t_{D}\right)_{n-1}\right] \times \\
& \frac{B \Delta p_{n}-\left(W_{e}\right)_{n-1}\left(p_{D}\right)_{\dot{n}}}{\left(p_{D}\right)_{n}-\left(t_{D}\right)_{n-1}\left(p_{D}\right)_{\dot{n}}}
\end{aligned}
$$

\section{Fetkovich Water Influx Model}

The Fetkovich model represents a simplified model to unsteady-state model of Van Everdingen Hurst which eliminates the use of superposition. The method utilizes the stabilized or pseudosteady-state aquifer productivity index and aquifer material balance in calculation of water influx into the reservoir. Fetkovich presented a generalized rate equation for an aquifer as shown in (31) [5], [17].

$$
q_{w}=J\left(\bar{p}-p_{R}\right)^{n}
$$

Fetkovich also wrote the aquifer material balance equation for constant compressibility system as shown in (30). Equations (31) and (32) can be combined to obtain Equation (33) [5].

$\bar{p}=-\left(\frac{p_{i}}{W_{e i}}\right) W_{e}+p_{i}$

$W_{e}=\frac{W_{e i}}{p_{i}}\left(\bar{p}-p_{R}\right)\left(1-e^{\frac{-j p_{i} t}{w}}\right)$

Fetkovich noted that (33) was derived at constant reservoir-aquifer boundary pressure, $\mathrm{P}_{\mathrm{R}}$ and constant average

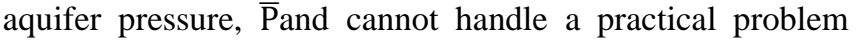
where the reservoir-aquifer boundary pressure is changing with time. Previous researchers such as van Everdingen and Hurst handled this problem by using superposition principle. Fetkovich handled this problem by re-evaluation of aquifer shut in pressure at each time and eliminate the need of superposition. Equation (34) to (40) represent the calculation 
of water influx by considering the use of Fetkovich method [5].

$$
\begin{aligned}
& \Delta W_{e n}=\frac{W_{e i}}{p_{i}}\left(\bar{p}_{n-1}-\bar{p}_{R n}\right)\left(1-e^{\frac{-j p_{i} \Delta t_{n}}{W}}\right) \\
& \bar{p}_{n-1}=p_{i}\left(1-\frac{W_{e}}{W_{e i}}\right)
\end{aligned}
$$

In case the aquifer is supported with injections, (35) is modified to consider the interference due to injections into the aquifer as shown in (36) [17].

$$
\begin{aligned}
& \bar{p}_{n-1}=-\left\lceil\frac{W_{e}+\sum_{2} j W_{e j}+\left(W_{p}-W_{i}\right) B_{w}}{W_{e i}}\right] p_{i}+p_{i} \\
& \bar{p}_{R n}=\frac{p_{R n-1}+p_{R n}}{2} \\
& \Delta t_{n}=t_{n}-t_{n-2} \\
& W_{e i}=\frac{c_{t}\left(\frac{\theta}{360}\right) \pi\left(r_{a}^{2}-r_{0}^{2}\right) h \emptyset p_{i}}{5.615} \\
& W_{e}=\sum \Delta W_{e n}
\end{aligned}
$$

\section{MATERIALS AND METHODS}

The methodology adopted in this research is to calculate water influx for edge and bottom water drive from pressure history data obtained from a field in The Niger Delta using Fetkovich Steady State Model. The calculated Water influx is used to determine the Recovery factors using The Material Balance Equation Algorithm (MBAL) software.

\section{A. MBAL Modelling}

The workflow for MBAL reservoir modelling for this study was generated by first defining the studied reservoir. Next step was to input the necessary PVT data, followed by the reservoir pressure and production data. After inputting these data, it was necessary to conduct a history matching process and to run simulations, which would yield prediction needed for the study. At this point desired results are achieved.

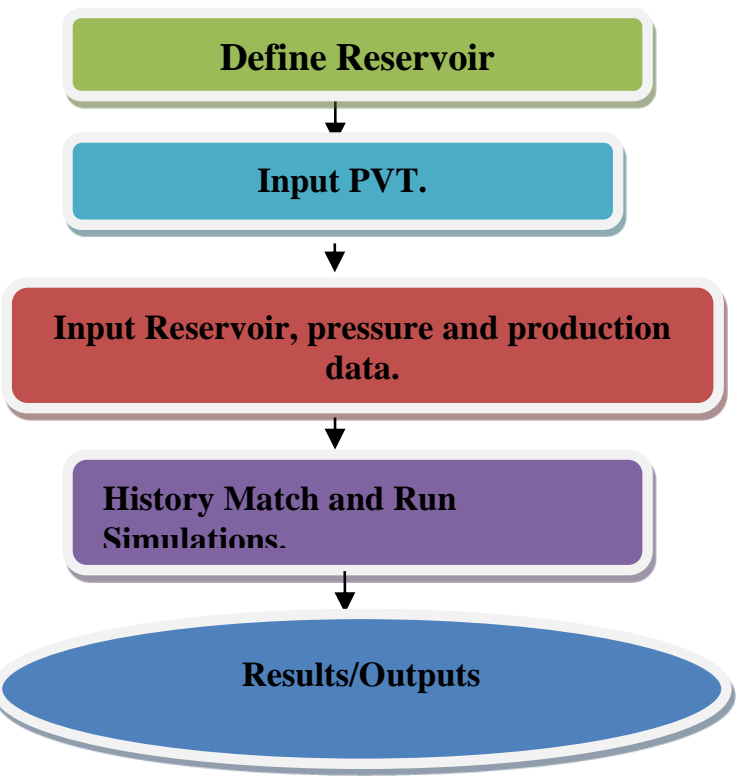

Fig. 7. Study workflow.

\section{B. Reservoir Data}

The key input data for building the MBAL model of the reservoirs include PVT, production and pressure, average reservoir/petro physical parameters, and depth versus pore volume from the geological static model. These input data are shown in Fig. 8 and Fig. 9.

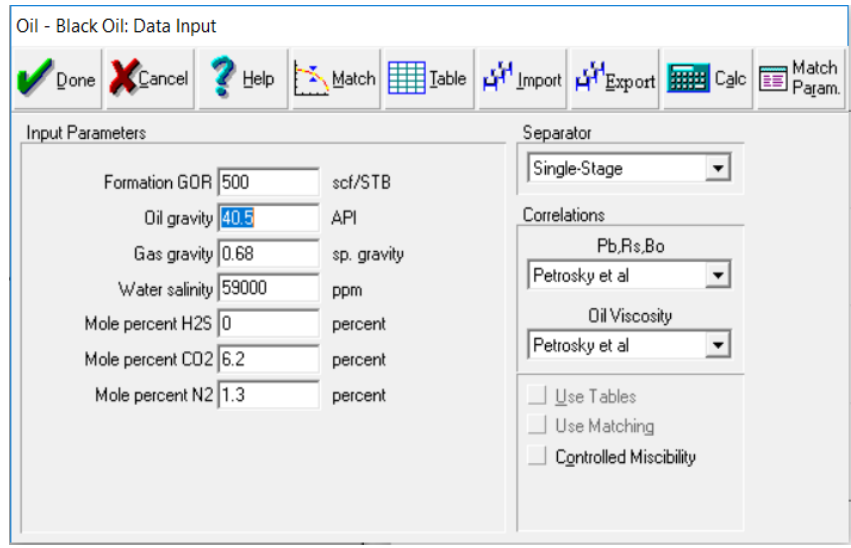

Fig. 8. Reservoir Fluid PVT Properties.

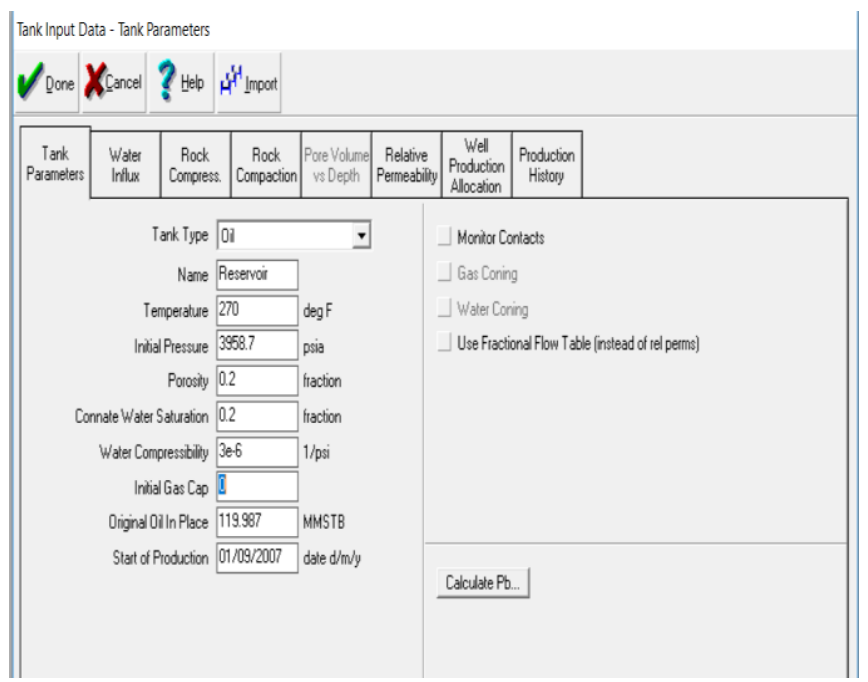

Fig. 9. Reservoir Rock and Fluid Properties.

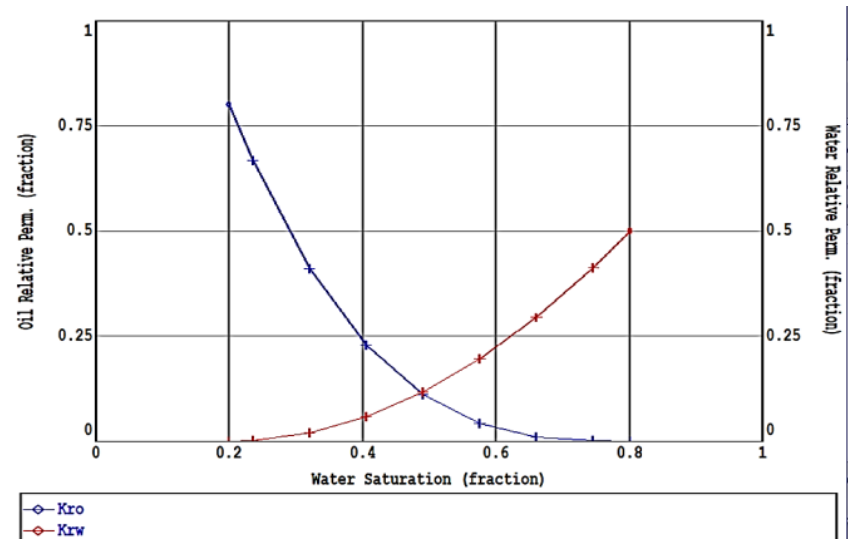

Fig. 10. Relative Permeability Profiles.

\section{Method Description}

Historic production data was imputed in to the MBAL Tank model. The production data was matched with the model simulation by regressing on rock and fluid parameters 
with high uncertainty. The match parameters were recorded as the base parameter and other sensitivity on aquifer parameters using the Fetkovich model for a bottom and edge water drive was performed to compare the relative increase in cumulative oil production. Some of the parameters used for sensitivity are:

1. Aquifer Volume;

2. Aquifer Permeability;

3. Dimensionless Reservoir Size.

\section{Modelling Assumptions}

The following assumptions were adopted:

1. The reservoirs are assumed to be a Tank.

2. The reservoirs are assumed to be homogenous (thus, they have uniform reservoir properties).

3. The reservoir Pressure and Temperature are uniformly distributed.

4. Uniform thickness.

5. Uniform porosity.

6. Constant rock compressibility.

7. Constant water compressibility.

\section{RESUlTS AND DISCUSSION}

\section{A. Reservoir Description}

Reservoir XYZ is a bottom water drive reservoir. Production input data was collected by well basis and collated historically to give the tank production history. Well 15/9-F5 was an oil producer and was later converted to a water injector due to high water production volumes from the well. The tank model (reservoir) consists of 7 wells as shown in Fig. 11.

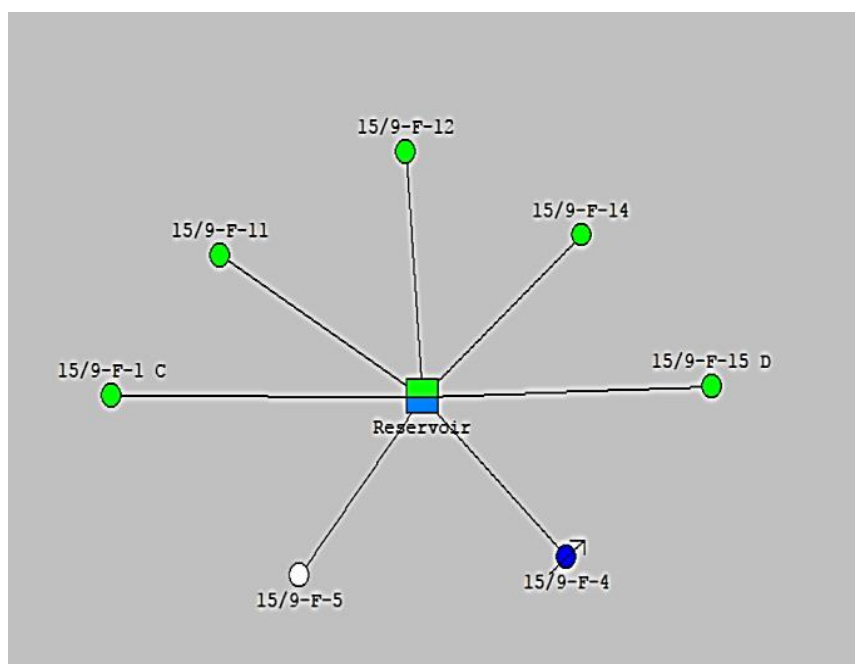

Fig. 11. Well and Reservoir Schematics.

Fig. 12 shows the analytical match for the reservoir production data. The energy plot in Fig. 13 indicates that the major drive energy of the reservoir is from the water injected, followed by fluid expansion.

The low water influx energy is in accordance as the aquifer is relatively small.

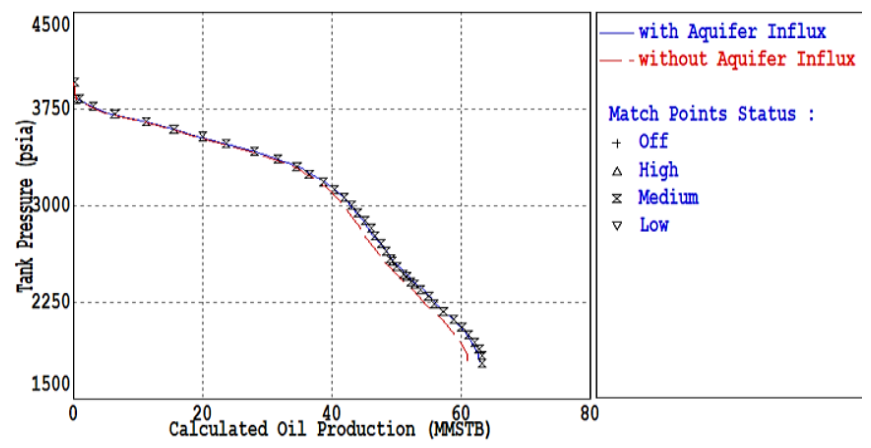

Fig. 12. Analytical Match of Well Production Data.

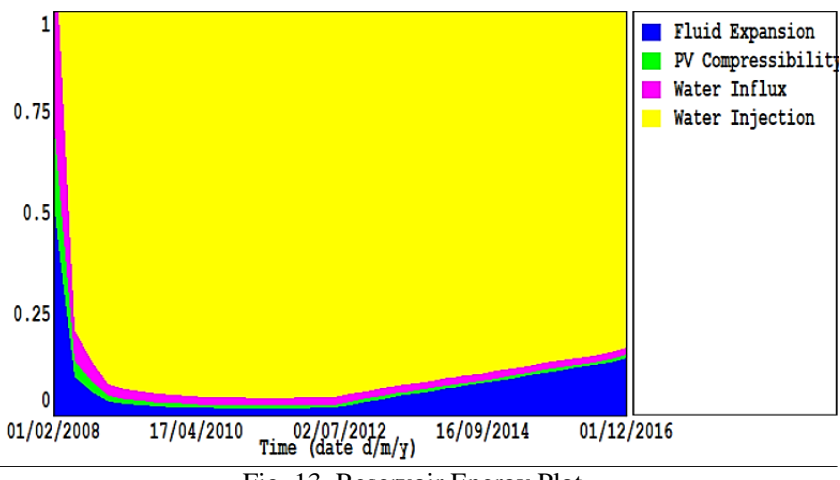

Fig. 13. Reservoir Energy Plot.

\section{B. History Matching}

The reservoir production (oil, water and gas) and pressures were matched (via tank and wells for quality check purpose) by regressing on reservoir parameters with high uncertainty (Outer/inner radius, reservoir radius, encroachment angle, aquifer constant). Reservoir parameters with lower uncertainty such as porosity and thickness were left constant.

The recovery efficiency in terms of cumulative from bottom water drive and edge water drive reservoir was studied using a material balance simulator MBAL. This was done by first matching the historic data with the Fetkovich aquifer model for both bottom and edge water drive while leaving Initial Oil in Place and other non-aquifer parameters constant.

The base case match of the historical data is shown in Table I.

TABLE I: BASE CASE PARAMETERS FOR EDGE AND BOTTOM WATER DRIVE

\begin{tabular}{ccc}
\hline Parameter & Edge Water Drive & $\begin{array}{c}\text { Bottom Water } \\
\text { Drive }\end{array}$ \\
\hline $\begin{array}{c}\text { Aquifer Permeability } \\
(\mathrm{mD})\end{array}$ & 300 & 300 \\
$\begin{array}{c}\text { Aquifer Volume } \\
\text { (MMRB) }\end{array}$ & 351.159 & 351.159 \\
Reservoir Size (ft) & 10541.4 & 1634.85 \\
\hline
\end{tabular}

The reservoir size (reservoir radius for bottom water drive and reservoir width for edge water drive) were expressed in dimensionless form to correlate both bottom and edge water drive reservoir size in terms of magnitude.

The dimensionless reservoir size is given by (41):

Dimensionless Reservoir Size $=\frac{\text { Reservoir Size }}{\text { Base Reservoir Size }}$ 


\section{Sensitivity Analysis}

\section{Aquifer Permeability}

Table II and Fig. 14 shows the sensitivity of cumulative oil produced with respect to change in aquifer permeability for a bottom and edge water drive aquifer.

TABLE II: CuMulative OIL PRODUCED With SENSITIVITY ON AQUIFER

\begin{tabular}{ccc}
\multicolumn{3}{c}{ PERMEABILITY } \\
\hline Aquifer Permeability & $\begin{array}{c}\text { Bottom Water Aquifer } \\
\text { Cum. Oil Produced }\end{array}$ & $\begin{array}{c}\text { Edge Water Aquifer } \\
\text { Cum. Oil Produced }\end{array}$ \\
\hline 50 & 63.07 & 63.07 \\
100 & 63.07 & 63.07 \\
150 & 63.08 & 63.07 \\
200 & 63.08 & 63.07 \\
250 & 63.08 & 63.08 \\
300 & 63.08 & 63.08 \\
350 & 63.08 & 63.08 \\
400 & 63.08 & 63.08 \\
450 & 63.08 & 63.08 \\
500 & 63.09 & 63.08 \\
\hline
\end{tabular}

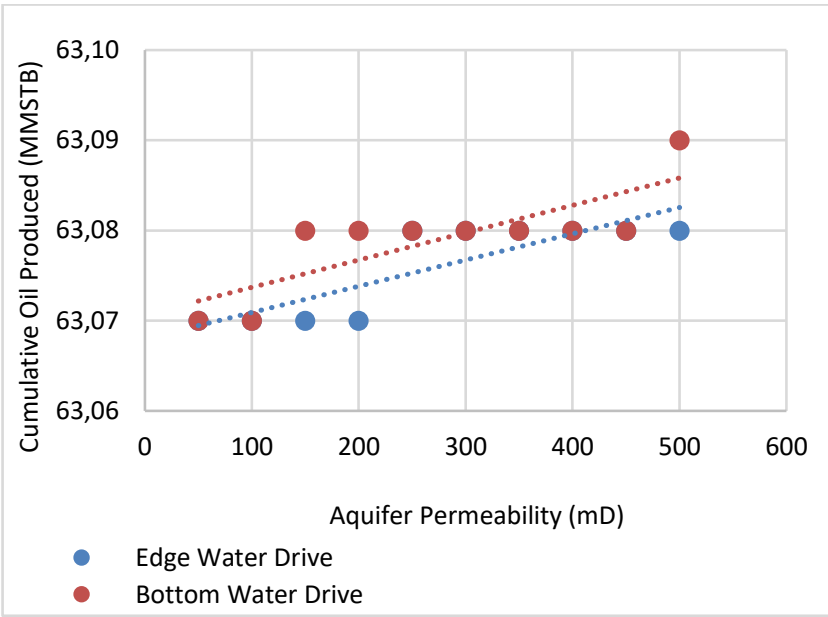

Fig. 14. Cumulative Oil Produced with Sensitivity on Aquifer Permeability.

Increase in aquifer permeability for bottom and edge water drive caused a slight increase in the cumulative oil produced. This increase was quite insignificant because the drive energy for the reservoir is majorly from water injection and water drive contribution in the drive index as shown in Fig. 13 is relatively small.

\section{Aquifer Volume}

Table III and Fig. 15 shows the sensitivity of cumulative oil produced with respect to change in aquifer permeability for a bottom and edge water drive aquifer. The average percentage increase in oil cumulative volume was $0.40 \%$ in favour of bottom water drive.

The average percentage increase in oil cumulative volume was $0.40 \%$ in favour of bottom water drive. Increase in aquifer volume for bottom water drive and edge water showed a linear increase in cumulative oil produced.
TABLE III: Cumulative OIL PRoduced With SENSITIVITY ON AQUiFER

\begin{tabular}{cccc}
\hline $\begin{array}{c}\text { Vquifer } \\
\text { Volume }\end{array}$ & $\begin{array}{c}\text { Bottom Water Aquifer } \\
\text { Cum. Oil Produced }\end{array}$ & $\begin{array}{c}\text { Edge Water Aquifer } \\
\text { Cum. Oil Produced }\end{array}$ & $\begin{array}{c}\text { \% Increase in } \\
\text { Total Volume }\end{array}$ \\
\hline 0 & 60.77 & 60.52 & $0.41 \%$ \\
50 & 61.02 & 60.77 & $0.41 \%$ \\
100 & 61.53 & 61.28 & $0.41 \%$ \\
150 & 61.78 & 61.53 & $0.41 \%$ \\
200 & 62.03 & 61.79 & $0.39 \%$ \\
250 & 62.29 & 62.03 & $0.42 \%$ \\
300 & 62.54 & 62.30 & $0.39 \%$ \\
350 & 63.05 & 62.79 & $0.41 \%$ \\
400 & 63.8 & 63.55 & $0.39 \%$ \\
450 & 64.06 & 63.8 & $0.41 \%$ \\
\hline
\end{tabular}

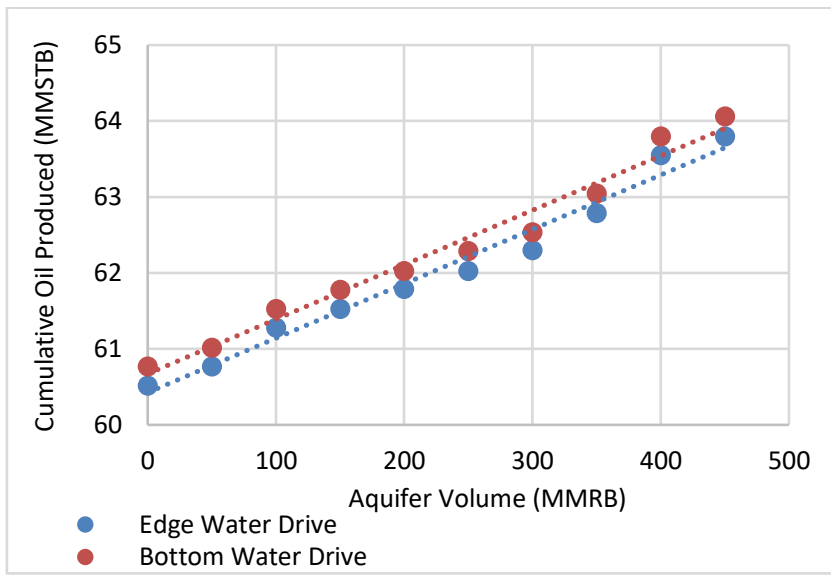

Fig. 15. Cumulative Oil Produced with Sensitivity on Aquifer Volume.

\section{Size of Reservoir}

Reservoir size was expressed in dimensionless terms as given by (41). Table IV and Table V show the sensitivity of reservoir size on cumulative oil produced for an aquifer volume of $300 \mathrm{MMRB}$ for bottom and edge water drive respectively.

TABLE IV: SENSITIVITY OF RESERVOIR SIZE ON CUMULATIVE OIL PRODUCED FOR AN AQUIFER VOLUME OF 300 MMRB FOR BOTTOM WATER DRIVE

\begin{tabular}{rrr}
\hline Reservoir Radius & Dimensionless Radius & Cum. Oil Produced \\
\hline 200 & 0.122335382 & 63.07 \\
400 & 0.244670765 & 63.07 \\
600 & 0.367006147 & 63.08 \\
800 & 0.48934153 & 63.08 \\
1000 & 0.611676912 & 63.08 \\
1200 & 0.734012295 & 63.08 \\
1400 & 0.856347677 & 63.08 \\
1600 & 0.97868306 & 63.08 \\
1800 & 1.101018442 & 63.08 \\
2000 & 1.223353825 & 63.08 \\
\hline
\end{tabular}

TABLE V: SENSITIVITY OF RESERVOIR SIZE ON CUMULATIVE OIL PRODUCED FOR AN AQUIFER VOLUME OF 300 MMRB FOR EDGE WATER DRIVE

\begin{tabular}{ccc}
\hline Reservoir Width & Dimensionless Width & Cum. Oil Produced \\
\hline 2000 & 0.18972812 & 63.07 \\
4000 & 0.379456239 & 63.07 \\
6000 & 0.569184359 & 63.07 \\
8000 & 0.758912478 & 63.07 \\
10000 & 0.948640598 & 63.08 \\
12000 & 1.138368718 & 63.08 \\
14000 & 1.328096837 & 63.08 \\
16000 & 1.517824957 & 63.08 \\
18000 & 1.707553076 & 63.08 \\
20000 & 1.897281196 & 63.08 \\
\hline
\end{tabular}




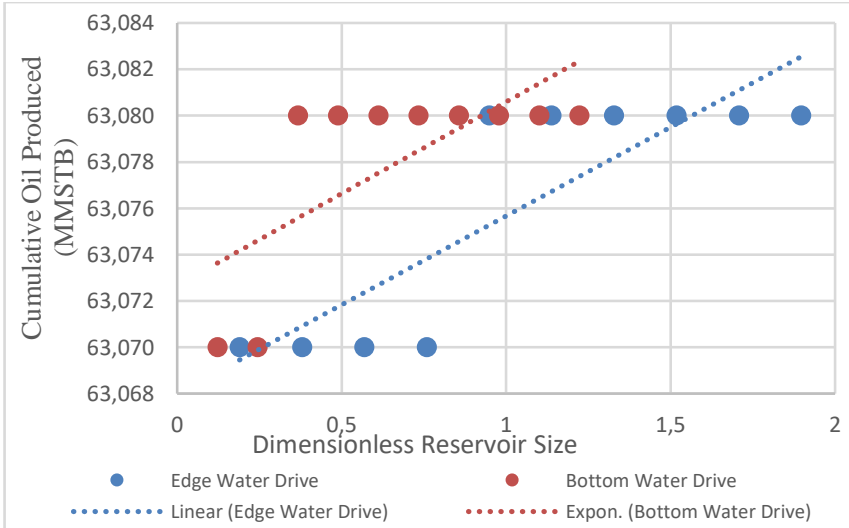

Fig. 16. Cumulative Oil Produced with Sensitivity on Reservoir Size at Aquifer Volume of $300 \mathrm{MMRB}$.

Fig 16 showed similar results to Fig. 14. Further analysis was done by increasing the aquifer volume to $30000 \mathrm{MMRB}$ to see the response to reservoir size as shown in Fig. 17.

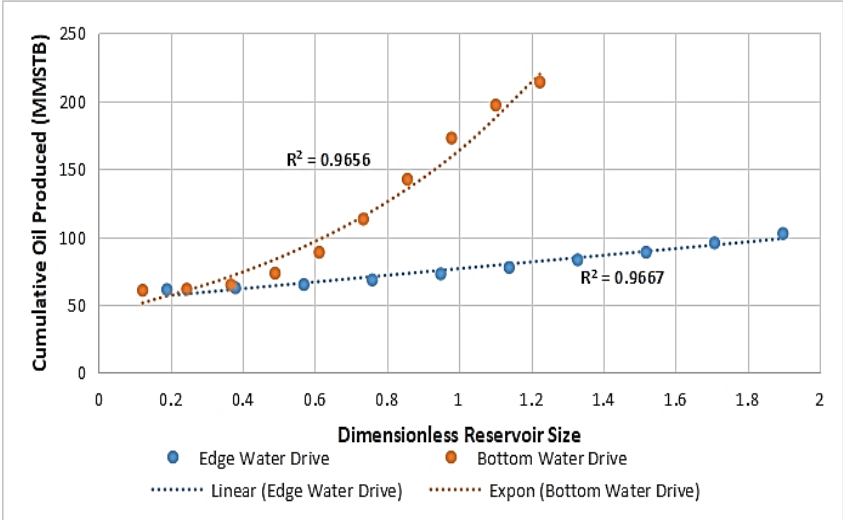

Fig. 17. Cumulative Oil Produced with Sensitivity on Reservoir Size at Aquifer Volume of 30000 MMRB.

Increase in aquifer volume and reservoir size increased cumulative oil produced for bottom and edge water drive. Cumulative oil produced from edge water drive increased linearly with increasing aquifer and dimensionless reservoir whereas bottom water drive increased exponentially with increasing aquifer volume and dimensionless reservoir size.

\section{CONCLUSION}

Sensitivity using Fetkovich water influx model showed that increase in reservoir size increases oil production exponentially in bottom water drive whereas edge water drive increased linearly. Aquifer volume, aquifer permeability showed linear relationship with bottom and edge water drive.

Bottom water drive is more effective than edge water drive and therefor bottom water drive reservoirs tend to give higher oil recovery compared to edge water drive. However, in addition to other channeling issues that affects edge and bottom water drive alike, water conning poses a critical concern for bottom water drive and if not properly managed would lead to early water break through and killing of the well.

\section{REFERENCES}

[1] Sospeter Maganga, (2017). Aquifer Characterization and Modelling a case study of Norne Field. 10(1), 1-18.

[2] Ahmed, T. (2006). Reservoir engineering handbook: Water influx (3rd ed.). Burlington: Gulf Professional Publishing.

[3] Knut, (2015). Petroleum Geoscience from Sedimentary Environments to rock physics DOI 10.1007/978-3-642-34132-8_8.

[4] Al-ghanim, J. A., Nashawi, I. S., \&Malallah, A. (2012). Prediction of Water Influx of EdgeWater Drive Reservoirs Using Nonparametric Optimal Transformations. Cairo: Society of Petroleum Engineers. doi: http://dx.doi.org/10.2118/150662-MS.

[5] Craft, B. C., Hawkins, M., \& Terry, R. E. (1991). Aplied Petroleum Resrvoir Engineering (2nd ed.). Englewood cliffs, New Jersy: Printice Hall, PTR Dake, L. P. (1978). Fundamentals of Reservoir Engineering (1st ed.). Amsterdam: Elsevier Science B.V.

[6] Shepherd, M., (2009). Factors Influencing Recovery from Oil and Gas Fields: AAPG Memoir 91, P.37-46.

[7] Jahn Wiley, M. Cook \& M. Graham., (1998). Hydrocarbon Exploration and Production. ISBN: 0444828834.

[8] Schlumberger, (2007). Aquifer Characterization Techniques (Methods in Water Resources Evaluation) ISBN 978-3-319-32137-0.

[9] Petrowiki. (2015). Water influx models. Retrieved April 27, 2019, from http://petrowiki.org/Water_influx_models.

[10] Leung, W.F., (1986). Numerical Laplace Inversion Methods: Application to the Calculation of the Water Influx from Aquifer Connected to petroleum Reservoirs, 30(1), 74-88, DOI: 10.1080/10916461003752611.

[11] Dake, L.P., (1978). Fundamentals of Reservoir Engineering.

[12] Allard, D. R., \& Chen, S. M. (1988). Calculation of Water Influx for Bottomwater Drive Reservoirs. Society of Petroleum Engineers, 03(02), 369-379. doi: https://doi.org/10.2118/13170-PA.

[13] van Everdingen, AF and Hurst, W., (1949). The Application of Laplace Transformation to Flow problems in Reservoirs Transaction of AIME, 186, 305-324.

[14] Klins, M. A., Bouchard, A. J., \& Cable, C. L. (1988). A Polynomial Approach to the Van Everdingen-Hurst Dimensionless Variables for Water Encroachment. Society of Petroleum Engineers, 3(01), 320 326. doi: http://dx.doi.org/10.2118/15433-PA.

[15] Marques, J.B. \& Trevisan., O.V. (2007). Classic Models of Calculation of Influx: A Comparative Study. Latin American \& Caribean petroleum Engineering Conference, Buenos. SPE - 107265-MS, dio.org/10.2118/107265-ms.

[16] Cater, R. D., \& Tracy, G. W. (1960). An Improved Method for Calculating Water Influx. Petroleum Transactions, AIME, 219, 415417.

[17] Fetkovich, M. J. (1971). A Simplified Approach to Water Influx Calculations-Finite Aquifer Systems. Journal of Petroleum Technology, 23(07), 814 - 828. doi: http://dx.doi.org/10.2118/2603PA. 